\title{
The incremental validity of the Triarchic model of psychopathy in replicating "The dark side of love and life satisfaction: Associations with intimate relationships, psychopathy and Machiavellianism”
}

\author{
Karina Bourbonnais ${ }^{\mathrm{a}}$ and Guillaume Durand ${ }^{\mathrm{b}, \otimes}$ \\ ${ }^{a}$ Résidence l’Érablière, Ottawa, Canada \\ ${ }^{\mathrm{b}}$ Department of Psychiatry and Neuropsychology, Maastricht University
}

\begin{abstract}
The present study is a replication of Ali and Chamorro-Premuzic (2010) [The dark side of love and life satisfaction: Associations with intimate relationships, psychopathy and Machiavellianism. Personality and Individual Differences, 48(2), 228-233]. We replicated the previous findings, supporting the significance of psychopathy and relationship components as predictors of life satisfaction, and extended our findings to the dark triad and the triarchic model of psychopathy. Our results suggest that the triarchic model of psychopathy provides incremental validity in predicting life satisfaction over the dark triad.
\end{abstract}

Keywords $₫$ Replication; Psychopathy; Relationships; Sexuality; Dark triad.
Acting Editor $\square \mathrm{De}-$ nis Cousineau (Université d'Ottawa)

Reviewers

- The Editor was unable to get an evaluation from the authors of the replicated study.

\section{gdura061@uottawa.ca}

KB: na; GD: 0000-0002-5418-4429

10.20982/tqmp.14.3.r001

\section{Introduction}

The 'dark triad' is a combination of three personality traits, namely Machiavellianism, subclinical narcissism, and subclinical psychopathy (Paulhus \& Williams, 2002). Individuals displaying high levels of Machiavellianism are considered charismatic, show high levels of social manipulation, a lack of concern for morality, and a strong desire to exploit others to their own advantage (Allsopp, Eysenck, \& Eysenck, 1991; Christie \& Geis, 1970). Narcissistic individuals tend to have an over-inflated ego and sense of self, are arrogant, feel entitled, and tend to often present themselves in a grandiose manner (Maxwell, Donnellan, Hopwood, \& Ackerman, 2011). While there is a general consensus regarding the definitions of Machiavellianism and narcissism, the concept of psychopathy and the traits included in the disorder are highly debated (Lilienfeld et al., 2012; Lynam \& Miller, 2012). Early conceptualizations of psychopathy defined psychopaths as individuals who are charming and stress resilient, but also as deprived from empathy, difficult to shame, impulsive, unreliable, egocentric, impersonal, having an imbalanced sexual life, and with a lack of life plan (Cleckley, 1988). With time, some researchers have focused on the maladaptive aspect of psychopathy, such as criminal activities and violence, while others have investigated some of the benefits associated with psychopathic traits, such as stress resiliency (Berg et al., 2013).

Multiple research have investigated the effect of the dark triad on traits related to satisfaction with life. A previous research supported that high levels of narcissism was positively associated with life satisfaction and happiness, while psychopathy and Machiavellianism were negatively or uncorrelated with both variables (Aghababaei \& Blachnio, 2015). Another study focusing on psychopathy and well-being supported that psychopathic traits related to social dominance was positively associated with happiness, presence of a meaning in life, personal growth, and hope, while psychopathic traits associated with impulsive antisociality were negatively associated with the aforementioned 
variables (Durand, 2018a).

Among the external variables which could influence the relationship between life satisfaction and the dark triad, past research identified intimate relationships as a potential covariate. In their study, Ali and ChamorroPremuzic (2010) investigated the effect of psychopathy, Machiavellianism, gender, age, sociosexual orientation and the relationship components of intimacy, commitment, and passion on life satisfaction in a sample of 291 individuals. Using structural equation modelling, the authors created a model explaining $25 \%$ of the variance in life satisfaction. The authors also found support for a negative relationship between psychopathy and Machiavellianism and both relationship components and satisfaction with life.

In their study, Ali and Chamorro-Premuzic (2010) did not include a measure of narcissism, which would have allowed covering completely the dark triad. Furthermore, the authors used the Levenson Self-Report Psychopathy Scale (LSRP; Levenson, Kiehl, \& Fitzpatrick, 1995) to assess psychopathy. While the LSPR was originally developed to investigate psychopathy in the general population, further research indicates that the LSRP focuses more on traits related to antisocial personality disorder (ASPD) than psychopathy (Lilienfeld \& Fowler, 2006). A key difference between the constructs is the exclusivity of traits related to affective and interpersonal features (e.g., empathy deficits, shallow moral emotions, immunity to stress) in psychopathy (Berg et al., 2013; Murphy, Lilienfeld, Skeem, \& Edens, 2016). Additionally, the LSRP demonstrates a limited association with bold interpersonal features of psychopathy, which covers the more adaptive side of psychopathy (e.g., social potency and stress immunity; Patrick, 2010; Poythress et al., 2010; Sellbom \& Phillips, 2013). Hence, the purpose of this research is to replicate the previous findings obtained by Ali and Chamorro-Premuzic (2010), as well as to determine if the inclusion of the complete dark triad, as well as an instrument of psychopathic traits covering the boldness component, would increase the predicted variance of satisfaction with life.

\section{Method}

\section{Participants}

A total of 541 participants were recruited online via websites dedicated to psychological research (www.callforparticipants.com, reddit.com/r/SampleSize). Although generally stigmatized by many researchers, several studies support the efficiency and validity of recruiting participants via web-based forums such as reddit.com (Casler, Bickel, \& Hackett, 2013; Jamnik \& Lane, 2017; Shatz, 2017). Examination of potential outliers was performed with the Triarchic Assessment Procedure of Inconsistent Responding (TAPIR; Mowle et al., 2017). Participants' score ranged from 0 to 11 , and therefore no protocol was removed. The sample consisted of 298 males and 243 females. Half of the participants $(48 \%)$ were university students. Participants were mostly in a serious relationship (47\%), single (46\%), or in a casual relationship (7\%). The majority of participants reported being located in North America (61\%) or Europe (26\%). The participants' mean age was 25.98 (SD = 7.67). All participants provided informed consent prior to completing the questionnaires. The participants did not receive a financial compensation for participating in this study.

\section{Materials and Procedure}

The procedure for this experiment was the same as the one used by Ali and Chamorro-Premuzic (2010), with the exception of the following differences. First, we replaced the Mach-IV inventory (Mach-IV; Christie \& Geis, 1970) and the LSRP by the short dark triad (SD3; Jones \& Paulhus, 2014). The SD3 is a 27-item instrument assessing Machiavellianism, narcissism, and psychopathy. Each factor includes 9 items, answered on a 5-point Likert scale. Additionally, we added a second, more detailed measure of psychopathic traits, the Triarchic Psychopathy Measure (TriPM; Patrick, 2010). The TriPM is a 58 items questionnaires rated on a 4point scale measuring psychopathy on three components, namely boldness, meanness, and disinhibition. Boldness refers to the adaptive nature observed in psychopathy, such as social dominance, fearlessness, and self-assurance. Meanness refers to aggression towards others, an absence of morality, and enjoyment through destruction. Disinhibition refers to impulsivity and a lack of restraint, representing behavioral deficits. While boldness is not a concept assessed with the LSRP, meanness and disinhibition are strongly correlated ( $r=.56$ and $r=.60$ ) to the factor 1 and 2 of the LSRP, respectively (Drislane, Patrick, \& Arsal, 2014). The sociosexual orientation inventory (SOI; Simpson \& Gangestad, 1991) and the Triangular love scale (TLS; Sternberg, 1997) remained unchanged from the original study.

\section{Results}

Table 1 provides descriptive statistics for the questionnaires used in the current study. A series of ANOVA was computed to investigate the role of gender on the present variables. On the TriPM, males displayed higher levels of boldness $(F(1,540)=18.189, p<.001)$, and meanness $(F(1,540)=15.560, p<.001)$, but lower levels of disinhibition $(F(1,540)=11.844, p=.001)$ than females. On the SD3, males displayed higher levels of Machiavellianism $(F(1,540)=6.721, p=.010)$, narcissism $(F(1,540)=$ 
Table 1 - Means, standard deviations, alpha coefficients, and gender difference. A positive difference signifies that men scored higher than women on average $(N=541)$

\begin{tabular}{lcccl}
\hline Scales & Mean & SD & Alpha & Gender difference \\
\hline Short Dark Triad (SD3) & & & & \\
Machiavellianism & 29.39 & 6.13 & .79 & $1.37^{*}$ \\
Narcissism & 23.10 & 5.96 & .73 & $1.46^{*}$ \\
Psychopathy & 19.40 & 5.61 & .71 & $1.10^{*}$ \\
Triarchic Psychopathy Measure (TriPM) & & & & \\
Boldness & 46.36 & 10.68 & .89 & $3.87^{*}$ \\
Disinhibition & 38.41 & 9.44 & .85 & $-2.78^{*}$ \\
Meanness & 33.02 & 9.05 & .88 & $3.04^{*}$ \\
Triangular love scale (TLS) & & & & \\
Intimacy & 38.35 & 8.97 & .91 & $-2.49^{*}$ \\
Passion & 28.53 & 10.80 & .93 & -1.81 \\
Commitment & 26.62 & 8.43 & .79 & $-2.60^{*}$ \\
Satisfaction with life scale (SWLS) & & & & \\
Satisfaction with life & 19.28 & 8.02 & .90 & -0.18 \\
Sociosexual orientation inventory (SOI) & & & & \\
Sociosexual orientation & 38.79 & 14.68 & .84 & $2.71^{*}$ \\
\hline
\end{tabular}

Note. Note. ${ }^{*}=\mathrm{p}<.05$

$8.050, p=.005)$, and psychopathy $(F(1,540)=5.176, p=$ .023) than females. On the TLS, females reported higher levels of intimacy $(F(1,540)=10.487, p=.001)$ and commitment $(F(1,540)=12.943, p<.001)$ than males. A last difference was observed on the SOI, where males reported higher scores $(F(1,540)=4.587, p=.033)$ than females.

Intercorrelations among age, dark triad variables (Machiavellianism, narcissism, and psychopathy), TriPM variables (boldness, meanness, and disinhibition), life satisfaction, sociosexual orientation, and love dimensions (intimacy, passion, and commitment) are shown in Table 2. Overall, satisfaction with life showed a positive association with narcissism, boldness, and the three components of love, and a negative association with psychopathy, disinhibition, and meanness.

In order to investigate the incremental validity of the narcissism component in predicting satisfaction with life, as well as the replacement of the psychopathy subscale by the TriPM, three regression analyses were computed. The first analysis included the following predictors: Machiavellianism, psychopathy, intimacy, passion, commitment, sociosexual orientation, age, and gender. The regression produced a significant model $(F(8,540)=12.233, p<.001)$ explaining $14 \%$ of the variance. Out of the entered predictors, only psychopathy ( $p=.001)$, intimacy $(p<.001)$, and sociosexual orientation ( $p=.031$ ) were significant. The second analysis kept the previous variables, but included narcissism to the predictors. The regression produced a significant model $(F(9,540)=21.080, p<.001)$ explaining $25 \%$ of the variance. Out of the entered predic- tors, only psychopathy ( $p<.001)$, narcissism $(p<.001)$, intimacy $(p<.001)$, and commitment $(p=.022)$ were significant. Lastly, for the third analysis, we removed psychopathy from the list of predictors, and added the three components of the TriPM. The regression produced a significant model $(F(11,540)=28.556, p<.001)$ explaining $36 \%$ of the variance. Of the entered variables, gender ( $p=.040)$, intimacy $(p<.001)$, commitment $(p=.045)$, boldness $(p<.001)$ and disinhibition $(p<.001)$ were the only significant predictors.

\section{Discussion}

Overall, the results of the current study support the findings obtained by Ali and Chamorro-Premuzic (2010) and provide new information on the role of the dark triad and intimacy on life satisfaction, increasing the explained variance by $11 \%$. Similarly to the previous study, we contend that males show higher levels of Machiavellianism, psychopathy, and sociosexual orientation. Regarding the components of love, the previous study only found an association between females and higher levels of commitment, while our study found an association between females and higher levels of commitment and intimacy.

The intercorrelations observed in the present study are similar to those previously obtained, with a few notable differences. First, albeit very weak, the results show a positive association between narcissism and commitment $(r=.19)$. While these results are surprising, individuals displaying high levels of other dark triad's traits, such as Machiavellianism and psychopathy, have been associated 
Table 2 a Bivariate Pearson correlation coefficients $(N=541)$

\begin{tabular}{|c|c|c|c|c|c|c|c|c|c|c|c|}
\hline & 1 & 2 & 3 & 4 & 5 & 6 & 7 & 8 & 9 & 10 & 11 \\
\hline \multicolumn{12}{|l|}{ 1. Age } \\
\hline 2. Machiavellianism & -.08 & & & & & & & & & & \\
\hline 3. Narcissism & .08 & $.30 *$ & & & & & & & & & \\
\hline 4. Psychopathy & .00 & $.50 *$ & $.39 *$ & & & & & & & & \\
\hline 5. Boldness & $.14 *$ & $.19 *$ & $.70 *$ & $.24 *$ & & & & & & & \\
\hline 6. Disinhibition & -.05 & $.24 *$ & .05 & $.54 *$ & $-.16 *$ & & & & & & \\
\hline 7. Meanness & -.07 & $.58 *$ & $.30 *$ & $.65 *$ & $.26 *$ & $.33 *$ & & & & & \\
\hline 8. Satisfaction with life & .05 & -.05 & $.30 *$ & $-.14 *$ & $.46 *$ & $-.34 *$ & $-.12 *$ & & & & \\
\hline 9. Sociosexual orient. & $.18 *$ & $.18 *$ & $.30 *$ & $.47 *$ & $.27 *$ & $.28 *$ & $.29 *$ & .03 & & & \\
\hline 10. Intimacy & -.01 & $-.17 *$ & .06 & $-.16 *$ & $.12 *$ & $-.16 *$ & $-.31 *$ & $.35 *$ & -.02 & & \\
\hline 11. Passion & $.13 *$ & -.09 & $.12 *$ & -.07 & $.17 *$ & -.08 & $-.17 *$ & $.25 *$ & .07 & $.46 *$ & \\
\hline 12. Commitment & .08 & $-.17 *$ & $.19 *$ & $-.25 *$ & -.05 & $-.18 *$ & $-.30 *$ & $.22 *$ & $-.35 *$ & $.49 *$ & $.41 *$ \\
\hline
\end{tabular}

Note . Note. Sociosexual orient. $=$ Sociosexual orientation. ${ }^{*}: p<.01$.

to using deceptive mating strategies (Durand, 2016; Dussault, Hojjat, \& Boone, 2013). It may be possible that highly narcissistic individuals may have a small interest in commitment, as long as the relationship valorizes them. Second, while narcissism was positively associated with satisfaction in life ( $r=.30$ ), the association between boldness and satisfaction in life was significantly stronger $(r=.46)$. This stronger correlation was also observed in the third regression analysis, whereas boldness replaced narcissism as a significant predictor of life satisfaction. It is possible that boldness, despite its strong correlation with narcissism $(r=.70)$, reflects the healthy facet of narcissism, such as self-assurance. Previous studies have associated narcissism with anger and resentfulness, while boldness has been associated with a wide range of adaptive behaviors, such as logical thinking and composure (Durand, 2018b; Twenge \& Campbell, 2003). These results suggest that, while dark personality traits such as the dark triad can explain the variance in predicting life satisfaction, the boldness component of the TriPM remains a stronger predictor than narcissism or Machiavellianism.

Overall, the current study supported the results obtained by Ali and Chamorro-Premuzic (2010), confirming that relationship components and psychopathy Factor 2 (disinhibition in the current study) as predictors of life satisfaction. Our extended findings further support that the TriPM, more precisely the boldness and disinhibition components, alongside the triangular love scale, provides the highest percentage of explained variance of life satisfaction.

\section{References}

Aghababaei, N., \& Blachnio, A. (2015). Well-being and the dark triad. Personality and Individual Differences, 86, 365-368. doi:10.1016/j.paid.2015.06.043
Ali, F., \& Chamorro-Premuzic, T. (2010). The dark side of love and life satisfaction: Associations with intimate relationships, psychopathy and machiavellianism. Personality and Individual Differences, 48(2), 228233. doi:10.1016/j.paid.2009.10.016

Allsopp, J., Eysenck, H. J., \& Eysenck, S. B. G. (1991). Machiavellianism as a component in psychoticism and extraversion. Personality and Individual Differences, 12(1), 29-41. doi:10.1016/0191-8869(91)90129-Y

Berg, J. M., Smith, S. F., Watts, A. L., Ammirati, R., Green, S. E., \& Lilienfeld, S. O. (2013). Misconceptions regarding psychopathic personality: Implications for clinical practice and research. Neuropsychiatry, 3, 63-74. doi:10.2217/npy.12.69

Casler, K., Bickel, L., \& Hackett, E. (2013). Separate but equal? A comparison of participants and data gathered via amazon's mturk, social media, and face-toface behavioral testing. Computers in Human Behavior, 29(6), 2156-2160. doi:10.1016/j.chb.2013.05.009

Christie, R., \& Geis, F. (1970). Studies in machiavellianism. London: Academic Press.

Cleckley, H. (1988). St. Louis: Mosby.

Drislane, L. E., Patrick, C. J., \& Arsal, G. (2014). Clarifying the content coverage of differing psychopathy inventories through reference to the triarchic psychopathy measure. Psychological Assessment, 26(2), 350362. doi:10.1037/a0035152

Durand, G. (2016). Digging in the Dark Triad: A replication of "Machiavellianism and Dating: Deception and Intimacy ". The Quantitative Methods for Psychology, 12(3), r6-r9. doi:10.20982/tqmp.12.3.r006

Durand, G. (2018a). Demystification of the relationship between psychopathy and happiness. Journal of Happiness Studies, 19(2), 381-395. doi:10.1007/s10902-0169823-0 
Durand, G. (2018b). Incremental validity of the durand adaptive psychopathic traits questionnaire above self-report psychopathy measures in community samples. Journal of Personality Assessment, online, 1-10. doi:10.1080/00223891.2018.1464456

Dussault, M., Hojjat, M., \& Boone, R. T. (2013). Machiavellianism and dating: Deception and intimacy. Social Behavior and Personality, 41(2), 283-294. doi:10.2224/ sbp.2013.41.2.283

Jamnik, M. R., \& Lane, D. J. (2017). The use of reddit as an inexpensive source for high-quality data. Practical Assessment, Research, and Evaluation, 22(5), 1-10.

Jones, D. N., \& Paulhus, D. L. (2014). Introducing the short dark triad (sd3) a brief measure of dark personality traits. Assessment, 21(1), 28-41.

Levenson, M. R., Kiehl, K. A., \& Fitzpatrick, C. M. (1995). Assessing psychopathic attributes in a noninstitutionalized population. Journal of Personality and Social Psychology, 68(1), 151-158.

Lilienfeld, S. O., \& Fowler, K. A. (2006). The self-report assessment of psychopathy. In C. J. Patrick (Ed.), Handbook of psychopathy (pp. 107-132). New York, NY: Guilford Press.

Lilienfeld, S. O., Patrick, C. J., Benning, S. D., Berg, J., Sellbom, M., \& Edens, J. F. (2012). The role of fearless dominance in psychopathy: Confusions, controversies, and clarifications. Personality Disorders: Theory, Research, and Treatment, 3(3), 327-340. doi:10.1037/ a0026987

Lynam, D. R., \& Miller, J. D. (2012). Fearless dominance and psychopathy: A response to lilienfeld et al. Personality Disorders: Theory, Research, and Treatment, 3(3), 341353. doi:10.1037/a0028296

Maxwell, K., Donnellan, M. B., Hopwood, C. J., \& Ackerman, R. A. (2011). The two faces of narcissus? an empirical comparison of the narcissistic personality inventory and the pathological narcissism inventory. Personality and Individual Differences, 50(5), 577-582. doi:10. 1016/j.paid.2010.11.031

Mowle, E. N., Kelley, S. E., Edens, J. F., Donnellan, M. B., Smith, S. T., Wygant, D. B., \& Sellbom, M. (2017). Development of an inconsistent responding scale for the triarchic psychopathy measure. Psychological Assessment, 29(8), 990-1000. doi:10.1037/pas0000395

Murphy, B., Lilienfeld, S., Skeem, J., \& Edens, J. F. (2016). Are fearless dominance traits superfluous in operationalizing psychopathy? incremental validity and sex differences. Psychological Assessment, 28(12), 1597-1607. doi:10.1037/pas0000288

Patrick, C. J. (2010). Triarchic psychopathy measure (tripm). Washington: PhenX Toolkit Online Assessment Cata$\log$.

Paulhus, D. L., \& Williams, K. M. (2002). The dark triad of personality: Narcissism, machiavellianism, and psychopathy. Journal of Research in Personality, 36(6), 556-563. doi:10.1016/S0092-6566(02)00505-6

Poythress, N. G., Lilienfeld, S. O., Skeem, J. L., Douglas, K. S., Edens, J. F., Epstein, M., \& Patrick, C. J. (2010). Using the pcl-r to help estimate the validity of two self-report measures of psychopathy with offenders. Assessment, 17(2), 206-219. doi:10 . 1177 / 1073191109351715

Sellbom, M., \& Phillips, T. R. (2013). An examination of the triarchic conceptualization of psychopathy in incarcerated and nonincarcerated samples. Journal of Abnormal Psychology, 122(1), 208-214. doi:10.1037/ a0029306

Shatz, I. (2017). Fast, free, and targeted: Reddit as a source for recruiting participants online. Social Science Computer Review, 35(4), 537-549. doi:10.1177/ 0894439316650163

Simpson, J. a., \& Gangestad, S. W. (1991). Individual differences in sociosexuality: Evidence for convergent and discriminant validity. Journal of Personality and Social Psychology, 60(6), 870-883. doi:10.1037/0022-3514.60. 6.870

Sternberg, R. J. (1997). Construct validation of a triangular love scale. European Journal of Social Psychology, 27(3), 313-335. doi:10.1002/(SICI)1099-0992(199705) 27:3<313::AID-EJSP824>3.3.CO;2-W

Twenge, J. M., \& Campbell, W. K. (2003). “isn't it fun to get the respect that we're going to deserve?” narcissism, social rejection, and aggression. Personality and Social Psychology Bulletin, 29(2), 261-272. doi:10.1177/ 0146167202239051

\section{Citation}

Bourbonnais, K., \& Durand, G. (2018). The incremental validity of the triarchic model of psychopathy in replicating "the dark side of love and life satisfaction: Associations with intimate relationships, psychopathy and machiavellianism”. The Quantitative Methods for Psychology, 14(3), r12-r17. doi:10.20982/tqmp.14.3.r001

Copyright (C) 2018, Bourbonnais and Durand. This is an open-access article distributed under the terms of the Creative Commons Attribution License (CC $\mathrm{BY})$. The use, distribution or reproduction in other forums is permitted, provided the original author(s) or licensor are credited and that the original publication in this journal is cited, in accordance with accepted academic practice. No use, distribution or reproduction is permitted which does not comply with these terms.

The Quantitative Methods for Psychology 
